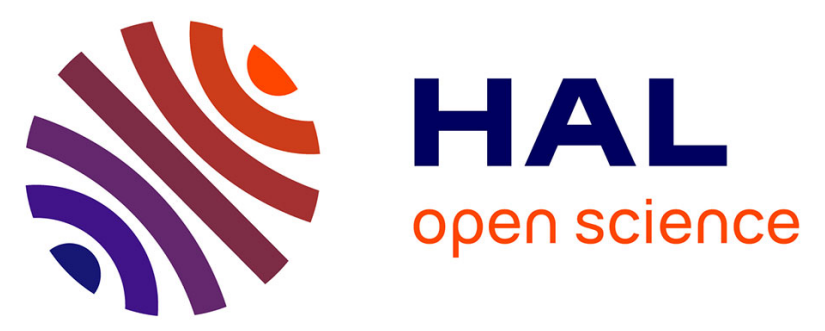

\title{
Modern Video-to-Video Communications to Enhance Citizens' Quality of Life and Create Opportunities for Growth in "Smart" European Cities
}

Ioannis P. Chochliouros, Anastasia S. Spiliopoulou, Ioannis M. Stephanakis, Evangelos Sfakianakis, Evangelia Georgiadou, Maria Belesioti, Luís Cordeiro, João Gonçalves

\section{To cite this version:}

Ioannis P. Chochliouros, Anastasia S. Spiliopoulou, Ioannis M. Stephanakis, Evangelos Sfakianakis, Evangelia Georgiadou, et al.. Modern Video-to-Video Communications to Enhance Citizens' Quality of Life and Create Opportunities for Growth in "Smart" European Cities. 10th IFIP International Conference on Artificial Intelligence Applications and Innovations (AIAI), Sep 2014, Rhodes, Greece. pp.1-12, 10.1007/978-3-662-44722-2_1 . hal-01391023

\section{HAL Id: hal-01391023 \\ https://hal.inria.fr/hal-01391023}

Submitted on 2 Nov 2016

HAL is a multi-disciplinary open access archive for the deposit and dissemination of scientific research documents, whether they are published or not. The documents may come from teaching and research institutions in France or abroad, or from public or private research centers.
L'archive ouverte pluridisciplinaire HAL, est destinée au dépôt et à la diffusion de documents scientifiques de niveau recherche, publiés ou non, émanant des établissements d'enseignement et de recherche français ou étrangers, des laboratoires publics ou privés. 


\title{
Modern Video-to-Video Communications to Enhance Citizens' Quality of Life and Create Opportunities for Growth in "Smart" European Cities
}

\author{
Ioannis P. Chochliouros ${ }^{1}$, Anastasia S. Spiliopoulou ${ }^{2}$, Ioannis Stephanakis ${ }^{2}$, \\ Evangelos Sfakianakis ${ }^{1}$, Evangelia Georgiadou ${ }^{1}$, \\ Maria Belesioti ${ }^{1}$, Luís Cordeiro ${ }^{3}$ and João Gonçalves ${ }^{3}$ \\ ${ }^{1}$ Research Programs Section, Fixed \\ Hellenic Telecommunications Organization (OTE) S.A., \\ 99 Kifissias Avenue, GR-151 24, Athens, Greece \\ \{ichochliouros, esfak, egeorgiadou, mbelesioti\}@oteresearch.gr \\ ${ }^{2}$ Hellenic Telecommunications Organization (OTE) S.A., \\ 99 Kifissias Avenue, GR-151 24, Athens, Greece \\ \{aspiliopoul, stephan\}@ote.gr \\ ${ }^{3}$ OneSource, Consultoria Inormatica, Lda, \\ \{cordeiro,john\}@onesource.pt
}

\begin{abstract}
The LiveCity Project effort structures a city-based "Living-Lab" and associated ecosystem to "pilot" and test live interactive high-definition videoto-video $(\mathrm{v} 2 \mathrm{v})$ on ultrafast wireless and wireline Internet infrastructure for the support of suitably selected public service use cases also involving a number of city user communities in five major European cities (Athens, Dublin, Luxembourg (city), Valladolid and Greifswald). The "core" target is to allow the citizens of a city to interact with each other in a more productive, efficient and socially useful way by using $\mathrm{v} 2 \mathrm{v}$ over the Internet in a variety of distinct use cases that discussed and analysed, in detail, in the present work.
\end{abstract}

Keywords: Future Internet (FI), interoperability, Living-Lab, quality of service (QoS), right of way (RoW), video-to-video (v2v) communication.

\section{The Scope of the LiveCity Initiative}

In the past decade several video-based communications have entered the market [1], to become usual in some domains including our working environment, our homes and applications on mobile devices ([2], [3]). However, we are still lagging behind from the goal of video calls being as easy and ubiquitous as phone calls are today - across any network and between variable devices. There are a number of existing gaps on the pathway to the realization of the Future Internet (FI) ([4], [5]) with live video-tovideo $(v 2 v)$. These "gaps" do appear at a number of different aspects (i.e.: end-user, service provider, network infrastructure, infrastructure design, service delivery 
platform, applications provider, end-point device). LiveCity aims to fill most -if not all- of the above mentioned gaps, by providing detailed and appropriate responses, per separate case. To this aim, LiveCity considers standard video encoding already available in "off-the-shelf" devices and seeks to resolve diverse issues relevant to the following matters: (i) Intercarrier interoperability; (ii) Service interoperability between different carriers; (iii) Compatibility with most used laptops, notebooks, smart-phones \& tablets; (iv) Promotion of the "First-for-consumers" option, by supporting simplicity of installation and usage; (iv) Seamless operation between endpoint devices; (v) Right of Way $(\mathrm{RoW})$ to be provided over various network types; (vi) Consideration of a large number of contacts addressable, together with globally reachable solutions; (vii) Integration of video application within vertical applications; (viii) Extension of the FI ecosystem to include mass-market in several types of communities [6].

LiveCity considers a variety of existing underlying network infrastructures and/or related facilities to explicitly serve its defined purposes [7]. This includes, for example: 4G wireless technology (i.e.: LTE and WiMAX) coupled with 3.5G wireless technology as well as fixed line xDSL broadband technology in those cases where fixed line is more appropriate than wireless, in urban environments. The "core" aim is to establish a real network with the involved cities together with the inclusion of a RoW without interference from unwanted traffic; this shall permit any potential user, in any of the involved cities, to "experience" live HD v2v. Thus, LiveCity is a pure "technological incorporation trial", that provides modern Internet-based services to over 2,750 users in the involved cities, via the implementation of selected pilot actions. LiveCity creates a wide ecosystem consisting of a variety of market "actors" including public service providers, network infrastructure operators, technology providers and subject matter experts, with the aim of supporting several well-defined public service use cases. LiveCity establishes a "Living-Lab"-like infrastructure [8] for the implementation of the selected pilots with diverse user communities, by sharing common service platforms [9]. It actually includes five European cities (i.e.: Athens, Dublin, Luxembourg (city), Valladolid and Greifswald) within an operational public-private-people (PPP) partnership-like framework [10] (as shown in Fig.1).

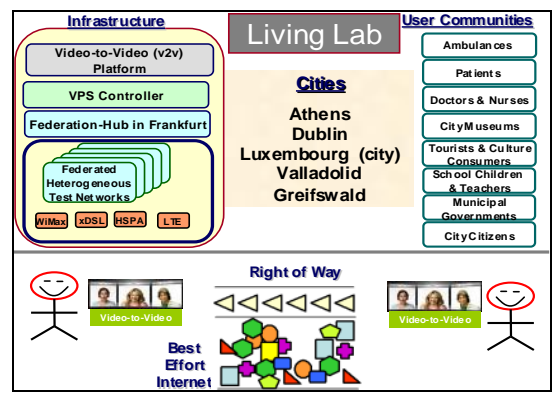

Fig.1. LiveCity "Living-Lab"-like infrastructure.

This "Living-Lab"-like scheme offers the possibility for a methodical user co-creation approach, which integrates v2v-based technology for the design and the final delivery of modern services, adopted to conform to the requirements of real-life use cases [11]. 
The original LiveCity concept permits to all involved actors-stakeholders to take into account both the global performance of the v2v service as well as its expected potential adoption by users. LiveCity structures a European network of "smart cities", where its smartness attribute originates from the capability to be interactive and live between (remote) locations between citizens in any appropriately connected city. LiveCity public service use cases are driven by public service operators to ensure a proper orientation towards fulfilling real market-born requirements. The technology and network partners come together to leverage both already existing and emerging network infrastructure combined with emerging "off-the-shelf" Virtual Path Slice (VPS) control software platforms and v2v applications software components, together with display/camera devices to realize video communication. This "unifying" approach leads to an operational and exploitable FI-based platform, which can later be rolled-out to other cities and communities, on a broader mass-market basis [12].

LiveCity supports technology that has the ability to massively scale. During the recent years, previous "barriers" to video calling have been remarkably reduced as a result of the widely penetrating high-bandwidth Internet access in most urban areas, together with lower cost of cameras and high-definition multimedia display devices in the market sector. LiveCity "joins together" all necessary components in a low-cost manner and offers a "testing ground" for a v2v mass-market deployment to cities in Europe. Also, it gathers and activates several user groups who can obtain economic and social benefit(s) from the proper deployment-use of live HD interactive v2v service. LiveCity assesses the effect of $\mathrm{v} 2 \mathrm{v}$ usage by these "actors" to demonstrate that a "homogenized service" can be available on a mass-market basis, over heterogeneous network infrastructure as actually happens in modern cities. The present public Internet provides a globally reachable "best-effort" network [13]. It is foreseen that FI should comprise a RoW for a user's traffic, lacking interference from unwanted traffic. Such RoWs are already implemented in virtual private networks by using diverse quality of service (QoS) mechanisms; nevertheless, a RoW without interference from unwanted traffic is not offered to the broad spectrum of users in the mass European market [14]. In order to offer maximum utility for all potential users, such RoW has to be globally reachable and must be supported on most -if not at allInternet environments, and at low -or at least at affordable- cost so that to be applicable by the users. LiveCity's explicit vision is to "conduct" v2v pilots for a range of user communities initially in the five participating European cities for a range of diverse applications and to support the network infrastructure with a proper RoW, in order that the inelastic traffic can get to the user and support the live experience [15].

\section{Developing Scenarios of Societal \& Economic Impact}

LiveCity's core aim is to permit the involved citizens of the participating cities to really interact with each other in a more creative, effective and simultaneously socially useful way, via the use of high quality v2v over the Internet [16]. Video-tovideo communication can be incorporated -or can be the central element- in a huge variety of services/applications, as a "means" to offer advanced services so that to: 
improve city administration; enhance education and learning capabilities for pupils/teachers; improve or extend cultural, educational and artistic applications offered by involved museums/cultural institutions, thus enhancing city experiences; support patient tele-monitoring and related medical applications in the eHealth sector, and; save patients' lives via $\mathrm{v} 2 \mathrm{v}$ inclusion in ambulances, to assist medical personnel for the realization of more effective emergency services. Furthermore, v2v also implicates significant environmental benefits via the reduction of fuel costs and carbon footprint, as it reduces travels within cities, in the scope of all previous purposes. To perform its promising visions, LiveCity is structured around the development of some selected and well-defined scenarios and/or use-cases, of major business and societal impact, as described below, per distinctive case:

Municipal Services: The use of $\mathrm{v} 2 \mathrm{v}$ for public administration and/or public information services can drastically enhance the access to and range of services reachable by the Internet. Likewise, this proves to the citizens' communities the effectiveness of a direct face-to-face communication for several municipal services which, in turn, leads to a more efficient user-service provider relationship and can so support the penetration of new services as opposed to voice-only or web-based services. Furthermore, this can decrease fuel costs and green-house emissions as a result of the reduction of travel and traffic within a city [17]. LiveCity focuses upon the provision of pilot platforms for use within specific local contexts. It undertakes extensive user requirements capture and development of use-cases drawn from working with real end-users. Besides, v2v can further enhance efficiency and utility of the proposed services-facilities and this is expected to improve accessibility and "comfort in use" of e-government services and physical service to the less ICT savvy, disabled and elderly citizens. As obvious, the above may have significant social and economic impact, resulting in remarkable benefits for individuals. (Effort for this purpose is deployed in the city of Valladolid, in Spain, and is mainly guided by Fundación Cartif and Ayuntamiento de Valladolid). Two specific use cases have been implemented: (1) the "Advisory service for entrepreneurs and enterprise initiatives" and; (2) the "Education for Adults" (see Fig.2). For the former, the main goal is to offer an integral service for entrepreneurs, having all the required and necessary support during the process of creation for a new enterprise so these initiatives could be properly arranged. In this scope, the phases of the intended activity comprise: (i) A video link for a Valladolid citizen to the interactive municipal online service office; (ii) A proactive advising session; (iii) Purpose/aim to explain -or to support- citizens about their questions concerning entrepreneur service, and; (iv) More approachable communications to be offered from the municipal offices to interested citizens.

Regarding the latter use case, most of the libraries in Valladolid are sited into multifunctional buildings called as "civic centres", where many activities are developed (i.e.: theatre, music, adult education). The "Education for Adult support" is a high-demand service and LiveCity aims to cover the need for the creation and development of volunteering platforms, through which the older people could "channel" their knowledge-experiences to "benefit" others, and enhance both their quality of living and social welfare of the community, in general. The goal here is to encourage the active participation of older people through the volunteer labour in technological and social projects, inter-alia with an innovating will that would imply 
an active social role and will also generate relationship and coexistence. The work performed -still being in progress- also includes the further refinement of testing methodologies for each use-case and will identify specific elements of the pilots which can bring added social, economic and environmental benefits.

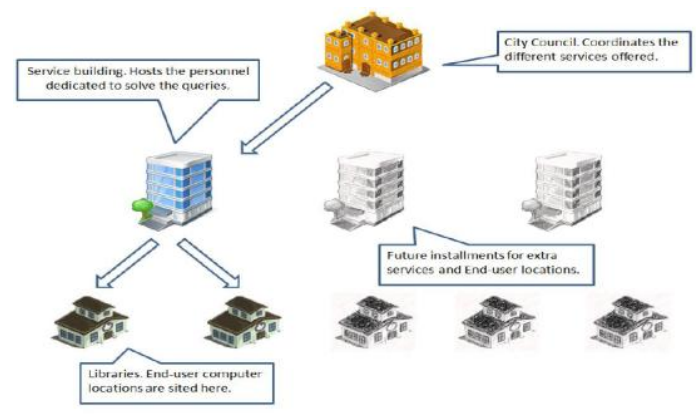

Fig.2. Physical locations for municipal services in the city of Valladolid.

City Education: As ICT turns out to be increasingly widespread within the environment of schools, a corresponding LiveCity pilot action focuses on the development of a framework where a v2v network is established between city secondary schools to improve learning and education, as well as to support/extend interactivity-collaboration between pupils and teachers. This latter option offers the possibility, to the involved schools, to work together to realize several projects via a proper "use and sharing" of any available resources and of teachers ([18], [19]).

Besides, this scope of interactivity can offer benefits of social value such as: (i) Ability, for leading teachers, to organize classes for students across the globe; (ii) Possibility to provide teachers' training facilities between the involved schools; (iii) Option for enhanced cultural exchanges between participating European schools, thus raising awareness of arts, science and social issues; (iv) Increase of parental participation in education, through the provision of teacher-parent training; (v) Capability to generate richer educational experiences to advance pupil attainment; (vi) Upgrading of the learning understanding of pupils; (vii) Better transfer of skills between pupils and teachers from different participating schools, in a cost-efficient way; (viii) Support of political ambitions -both at EU and national level- to get better education standards; (ix) Support for the formation of an EU-wide education system, potentially reachable by all sections of society, able to sustain gain of knowledge through access to expert teachers; (x) Contribution to the generation of new knowledge, new ideas for learning and teaching through the use of video archives. Work to fulfill these expectations takes places in Dublin and in Athens.

User scenarios that are under exploration include using $\mathrm{v} 2 \mathrm{v}$ in a literacy education scenario, in the subject area of arts and in a sport education scenario. LiveCity implements two educational use cases by using FI capabilities to realize v2v in the involved schools in Dublin. These are: (1) The "School-to-School" (S2S) use case, where $\mathrm{v} 2 \mathrm{v}$ is established between schools for applications such as projects, culture awareness and other topics (as in Fig.3a), and; (2) the "Ask-the-Expert Channel" use case, where $\mathrm{v} 2 \mathrm{v}$ is used between children/students after school from their school to a 
central educational support provider. The purpose is to assist and enhance school activities (see Fig.3b). (The effort is mainly realized by Skryne School, in cooperation with other LiveCity partners such as RedZinc Services Ltd., QuartzSpark Ltd., Magnet Networks Ltd. and OneSource, Consultoria Informatica Lda).

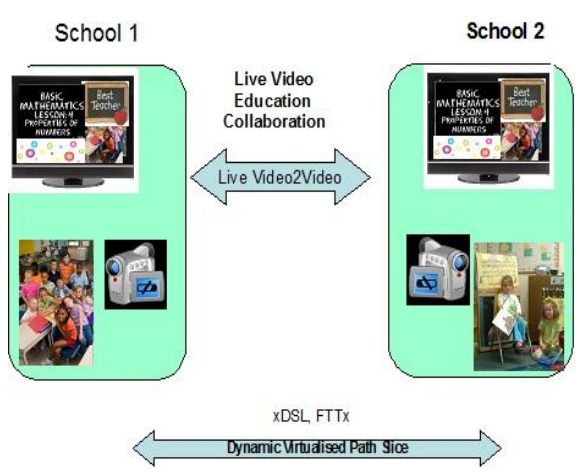

Fig.3a. The "School-to-School" use case, with video interaction.

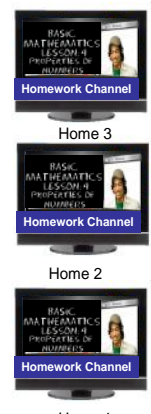

Home 1

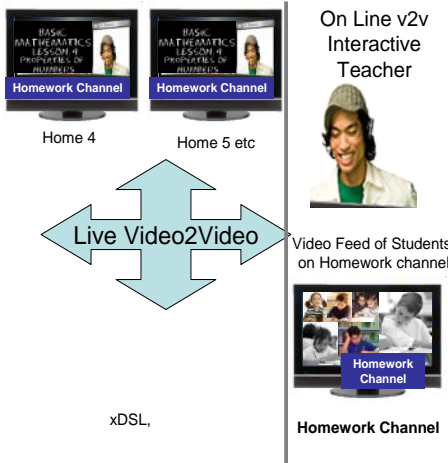

Fig.3b. The "Ask-the-Expert Channel" use case, with video interaction.

City Experiences: With the purpose of enhancing tourism, cultural and city marketing information, a dedicated LiveCity pilot action considers $\mathrm{v} 2 \mathrm{v}$ use between museums and/or involved cultural institutes. In the same context, local city administrations can also be involved in the related effort "by choosing the figure and further promoting it". This "opens new horizons" in the corresponding domains as it can widen the capability of any involved legal entities -located across Europe- to offer modern and shared (occasionally mobile) content and/or experiences for both real and virtual visitors.

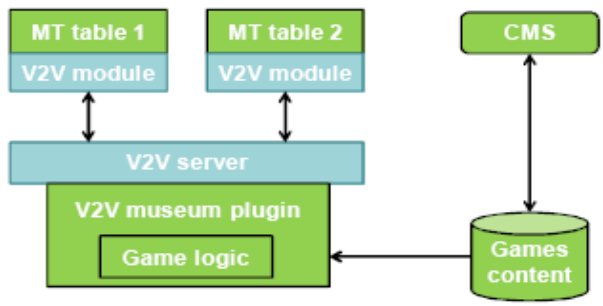

Fig.4. Diagram of the proposed solution for the LiveCity Museum v2v City Experience use case.

This use case also implicates for one more beneficial impact as it can improve the interactive and social nature of the (participating) museum's exhibits and can thus "be a magnet" for extra visitors who will stay connected for longer periods of time. Through the use of suitable IT equipment which also includes multi-touch tables (MTs), cameras, TV screens and appropriate content management system (CMS) -as shown in Fig.4- this initiative can "make bigger and longer" the cultural experience also with the intention of covering a greater part of the involved city; this can be done 
by opening-up the possibility for creating exhibits with "mixed" content which is created by the original museum in cooperation with real-world originating content, potentially promoted/created by museum visitors. The core aim is to enable telecom museums visitors to "interact with one-another in a joint experience", via the deployment of fitting games [20]. Games should: be of a well-known concept and be familiar to visitors; flexible and adjustable to different content; multiplayer, but can also be played alone; enhance knowledge about museum exhibits (local and remote).

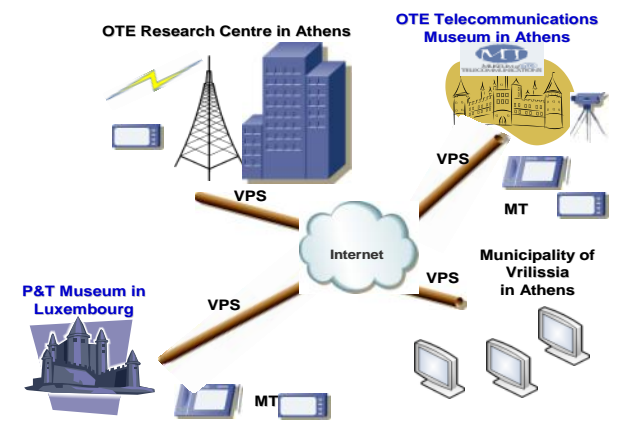

Fig.5. The LiveCity Museum v2v City Experience use case.

Developed applications are useful for the participating museums to generate common, shared and multi-user experiences that include visitors both on- and off-site; this is a remarkable aspect as it implicates potential for "cooperation and content sharing" between geographically diverse locations. Such actions also promote the development of cultural-oriented tourism within the participating cities as well as in a wider EU framework. This can advance the visits and profitability of tourist locations and operate as "a way of creating new revenue streams" [21]. The pilot takes place between the "twin" cities of Athens and Luxembourg (via an active collaboration between OTE's Telecoms Museum and the P\&T Museum, correspondingly) as shown in Fig.5. (The main partners participating to the realization of this use case are OTE, the University of Luxembourg/SnT and the Municipality of Vrilissia-Athens).

City Emergency: This specific use case considers a city hospital emergency department (ED) team who has reduced/limited effectiveness because they cannot "see" -and optimally treat- the patient remotely, during the critical "golden hour" before the patient gets to hospital in the ambulance [22]. The related pilot activity experiments with live high-quality $\mathrm{v} 2 \mathrm{v}$ between the ambulance and the hospital and examines options to enhance patient outcomes (e.g., shorter time to administer thrombolysis clot busting drugs in the case of a stroke or survival in a case of a polytrauma) and, consequently, to have early availability of expert opinion at the scene [23], when necessary (see Fig.6a). This implicates speedier access to senior decision making and optimal referring to appropriate centre to facilitate further medical management-treatment [24]. The three specific cases which are being implemented with ambulance video link are: (i) Elevation Myocardial infarction fast track; (ii) Cerebrovascular event/stroke, and; (iii) Entrapment of injured patient (trauma) [25]. The corresponding pilot action takes place in the city of Dublin (via the 
participation of RCSI (Royal College of Surgeons in Ireland) personnel (stationed at the Beaumont Hospital) and working collaboratively with Health Service ExecutiveHSE and Telefónica O2 Ireland Ltd.).

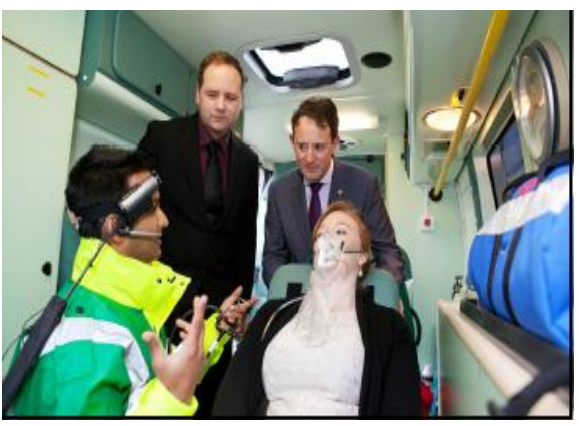

Fig.6a. Use of v2v in Ambulances for the City Emergency use case

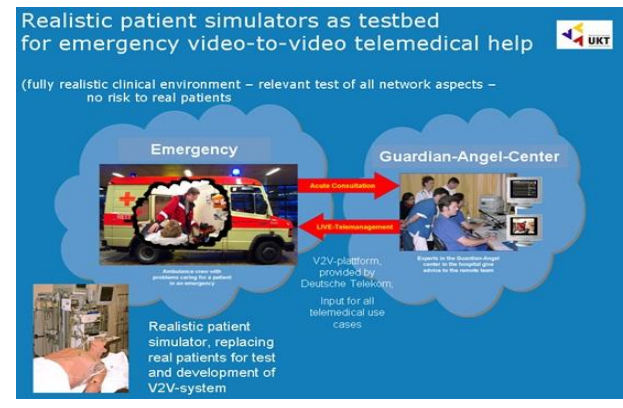

Fig.6b. Simulation of the Medical Emergency use case

This use case is also to be simulated and is expected to be later implemented in a live clinical setting. A realistic patient simulator test phase [26] will allow the LiveCity to adopt the needed technical and educational needs for the real world implementation (see Fig.6b). Simulation takes place in the city of Greifswald, in Germany (via the participation of the Ernst-Moritz-Arndt University of Greifswald).

City eHealth: This use case is related to a glaucoma patient who needs monitoring and/or medical treatment (see Fig.7). The use of v2v between the home of a patient and hospital/clinic support group enables medical personnel (GP, doctor specialist or nurse) to provide enhanced support and have regular contact with that patient during his/her medical treatment, at lower cost and higher utility [27], [28]. By being able to provide faster and more reliable video feeds and medical telemetry tests (telediagnosis and tele-monitoring) [29], LiveCity facilitates and improves: the quality of the health service as more often than usual contacts may apply; the quality of life, and; ambient-living conditions for the patients.
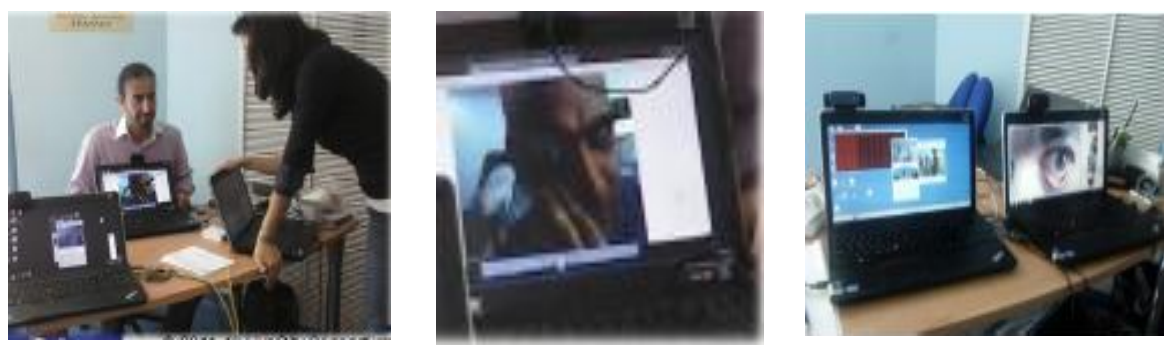

Fig.7. City eHealth use case, for patient glaucoma treatment.

The inclusion of $\mathrm{v} 2 \mathrm{v}$-that may be also accessible at community level and at mass accesses and least possible price- can provide better solutions to the health problems and it can result in fewer complications and lower medical costs, in parallel with 
reduced travels and traffic. This pilot initiative is actually deployed in Athens (via the participation of the National \& Kapodistrian University of Athens-UoA, mainly in cooperation with the Attikon University Hospital and Innovators S.A.).

All previous use cases are fairly representative among those "shaping the wider profile" of citizen's living in a "smart city" where Internet-based facilities are conceived as the "means" to perform transition to a more inclusive and digitallybased economy and society. Therefore, LiveCity covers a variety of services that are expected to be developed conformant to real users' needs. As v2v planned actions are realized via the joint effort of city authorities and (public) service operators, resulting outcome is important, applicable and beneficial in real-life terms. This can also further strengthen the role of the "user-citizen" in the social and technological innovation lifecycle. For all use cases, stakeholder evaluation and key performance indicators (KPIs) are measured, analyzed and disseminated, appropriately [30]. The essential hypothesis is that these indicators -once properly identified- can then be significantly enhanced with the usage of $\mathrm{v} 2 \mathrm{v}$ communication [31]. Work, for this purpose, is coordinated for all use cases by the Brunel University, UK.

\section{Concluding Remarks}

The previously discussed LiveCity use cases are all "active and indispensable parts" of the local cities ecosystems and may have major benefits to improve citizens' living standards. The full scope of the related effort focuses upon interoperable actions for testing and validation processes of the proposed facilities, for the uptake of new services and for the benefit of multiple recipients, in real and applicable scenarios [32]. It is worth mentioning that end-users are dynamic "participants" and also "assessors" of the proposed solution(s), while their feedback is taken into account and affects further evolutionary steps.

LiveCity creates of a city-based Living-Lab and associated ecosystem to pilot live interactive high-definition $\mathrm{v} 2 \mathrm{v}$ on a variety of existing Internet infrastructure, among 5 EU cities. It implements public service use cases with over 2,750 involved users, by focusing on the application of $\mathrm{v} 2 \mathrm{v}$ in a number of selected domains (i.e.: Municipal Services, City Experience, Education and Learning, Emergency and eHealth) with a significant validity for the citizen, also intending enhance a range of KPIs. It also aims to support the acceleration of $\mathrm{v} 2 \mathrm{v}$ mass-market start across cities in Europe, by showcasing successful use cases, producing "how-to guides" and providing a "get-up and go" solution to public service operators.

LiveCity considers the proper use and the exploitation of already existing infrastructures-technologies that are truly offered by market operators and so its solutions can be applicable without necessitating any additional investment of resources. It implements selective pilots for motivating the development of innovative FI-based platforms and services; this is performed in a "balanced" partnership scheme including "actors" from different sectors (industry and business sector, citizens, public authorities and academia) with the aim of developing possible "synergies" of value [33]. Expected results should be important for market development, for 
supporting local economies and for deploying new services and products, implicating social, technical and economic impacts [34].

Acknowledgments: The present article has been structured in the context of the LiveCity ("Live Video-to-Video Supporting Interactive City Infrastructure") European Research Project and has been supported by the Commission of the European Communities - DG CONNECT (FP7-ICT-PSP, Grant Agreement No.297291). The present work has been realized by the support of all involved LiveCity partners and their contributions to the various work packages, per case.

\section{References}

1. Wang, Y., et al.: Video Processing and Communications. Prentice Hall (2002).

2. Wang, H., Kondi, L., Luthra, A., Ci, S. : 4G Wireless Video Communications. John Wiley \& Sons (2009).

3. Al-Mualla et al.: 4G Wireless Video Coding for Mobile Communications: Efficiency, Complexity and Resilience. Elsevier Science, Academic Press (2009).

4. Future Internet Assembly (FIA): Position Paper: Real World Internet (2009). [http://rwi.future-internet.eu/index.php/Position_Paper].

5. Tselentis, G., Domingue, L., Galis, A., Gavras, A., et al.: Towards the Future Internet - A European Research Perspective. IOS Press (2009).

6. Organization for Economic Co-operation and Development (OECD): The Seoul Declaration for the Future of the Internet Economy. Paris, France (2008).

7. Chochliouros, I.P., et al:: Developing Innovative Live Video-to-Video Communications for Smarter European Cities. In L. Iliadis et al. (Eds.), Proceedings of the AIAI-2012 Conference, vol. 382, pp. 279--289. Springer, Heidelberg (2012).

8. Chochliouros, I.P., Spiliopoulou A.S., et al.: Living Labs in Smart Cities as Critical Enablers for Making Real the Modern Future Internet. In L. Iliadis et al. (Eds), Proceedings of the EANN-2013 Conference, vol.384, pp. 312--321,Springer Heidelberg (2013).

9. Mulvenna, M., et al.: Living Labs as Engagement Models for Innovation. In P. Cunningham and M. Cunningham (Eds.), Proceedings of eChallenges-2010, pp. 1--11, International Information Management Corporation (IIMC) (2010).

10. Commission of the European Communities: Communication on "A Public-Private Partnership on the Future Internet" [COM(2009) 479 final, 28.10.2009]. Brussels (2009).

11. Kusiak, A.: Innovation: The Living Laboratory Perspective, Computer-Aided Design and Applications, 4(6), 863--876, (2007).

12. Chesbrough H.: Open Innovation: The New Imperative for Creating and Profiting from Technology. Boston, Harvard Business School (2003).

13. Sood, A., Tellis, G.: Technological Evolution and Radical Innovation, Journal of Marketing, 69(3), 152--168, (2005).

14. Commission of the European Communities: Communication on "Future Networks and the Internet" [COM(2008) 594 final, 29.09.2008]. Brussels, Belgium (2008).

15. Klaue, J., Rathke, B., Wolisz, A.: Evalvid - A Framework for Video Transmission and Quality Evaluation. In Proceedings of the 13th International Conference on Modelling Techniques and Tools for Computer Performance Evaluation, pp. 255--272 (2003).

16. Afuah, A., Tucci, C.L.: Internet Business Models and Strategies: Text and Cases. McGrawHill (2000).

17. Parkinson, M., et al.: H.: Competitive European Cities: Where Do The Core Cities Stand?, European Institute for Urban Affairs, Office of the Deputy Prime Minister, London (2003). 
18. Chochliouros, I.P., et al.: Enhancing Education and Learning Capabilities via the Implementation of Video-to-Video Communications. In L. Iliadis et al. (Eds.), Proceedings of the AIAI-2012 Conference, vol. 382, pp. 268--278. Springer, Heidelberg (2012).

19. European Commission, Information Society and Media: Education and Information Society: Linking European Policies. Luxembourg (2006).

20. Montola, M., Stenros, J., Waern, A.: Pervasive Games: Theory and Design, Morgan Kaufmann, San Francisco, CA, (2009).

21. Chochliouros, I.P., McCall, R., Popleteev, A., et al: (Semi-) Pervasive Gaming Educational and Entertainment Facilities via Interactive Video-to-Video Communication over the Internet, for Museum Exhibits. In H. Papadopoulos et al. (Eds.), Proceedings of the AIAI2013 Conference, vol. 412, pp. 474--485. Springer, Heidelberg (2013).

22. Palma, D., Gonçalves J., et al: Tutamen: An Integrated Personal Mobile and Adaptable Video Platform for Health and Protection. In H. Papadopoulos et al. (Eds.), Proceedings of the AIAI-2013 Conference, vol. 412, pp. 442--451 Springer, Heidelberg (2013).

23. Padki, A., et al: Healthcare Provider Perspective on Telemedicine in Pre-Hospital Care: A LiveCity Survey of Doctors and Nurses in Emergency Department of Beaumont Hospital, Dublin. In IAEM (Ed.), Proceedings of the Annual Irish Association for Emergency Medicine 2013 Conference (2013).

24. Houlihan, A.P., et al: Perceptions and Views of Use of Telemedicine in Emergency Care: A LiveCity Survey of Patients attending the Emergency Department. In IAEM (Ed.), Proceedings of the Annual IAEM 2013 Conference (2013).

25. Panayides, A., et al:: An Overview of Recent End-to-End Wireless Medical Video Telemedicine Systems Using 3G. In IEEE (Ed.), Proceedings of the Annual Conference on Engineering in Medicine and Biology Society (EMBC), pp. 1045--1048. IEEE (2010).

26. Metelmann, B., Metelmann, C., et al.: Videoübertragung in Echtzeit zur Verbesserung der Notfallmedizin. Accepted paper to appear in the Proceedings of the National German Congress VDE-2014 in Frankfurt am Main, Messe, Germany (October 20-21, 2014).

27. Diamantopoulos, P., Bompetsis, N., et al.: E-health Applications for Smart Cities Infrastructures based on Live Video-to-Video Solutions. Accepted paper to appear in the Proceedings of the EuCNC-2014 Congress in Bologna, Italy (June 23-26, 2014).

28. Stamatelatos, M., et al: Video-to-Video for e-Health: Use Case, Concept and Pilot Plan. In L. Iliadis et al. (Eds.), Proceedings of the AIAI-2012 Conference, vol. 382, pp. 311--321. Springer, Heidelberg (2012).

29. Corchado, J., et al.: Using Heterogeneous Wireless Sensor Networks in a Telemonitoring System for Healthcare, IEEE Trans. Inf. Technol. Biomed., 14(2), 234--240 (2010).

30. Weerakkody, V., et al.: Utilising a High-Definition Live Video Platform to Facilitate Public Service Delivery. In L. Iliadis et al. (Eds.), Proceedings of the AIAI-2012 Conference, vol. 382, pp. 311--321. Springer, Heidelberg (2012).

31. Molnar, A., et al.: A Framework Reference for Evaluating User Experience when Using High Definition Video-to-Video to Facilitate Public Services. In Y.K. Dwivedi et al. (Eds.), Proceedings of the IFIP 8, vol 402, pp. 436--450. Springer (2013).

32. Commission of the European Communities: Communication on Europe 2020: A Strategy for Smart, Sustainable and Inclusive Growth [COM(2010) 2020 final, 03.03.2010]. Brussels, Belgium (2010).

33. Blumenthal M.S., and Clark, D.D.: Rethinking the Design of the Internet: The End-to-End Arguments vs. The Brave New World, ACM Trans. on Internet Tech. 1(1), 70--109 (2001).

34. Castells, M.: The Information Age: Economy, Society, and Culture. Oxford, UK: Blackwell (1996). 